\title{
State-Owned versus Township and Village Enterprises in China
}

\author{
Enrico C. Perotti
}

University of Amsterdam and CEPR

Laixiang Sun

International Institute for Applied Systems Analysis, Laxenburg, Austria

Liang Zou

University of Amsterdam

RR-99-11

November 1999

Reprinted from Comparative Economic Studies, XLI, No. 2-3 (Summer/Fall 1999), pp. 151-179 
Research Reports, which record research conducted at IIASA, are independently reviewed before publication. Views or opinions expressed herein do not necessarily represent those of the Institute, its National Member Organizations, or other organizations supporting the work.

Reprinted with permission from Comparative Economic Studies, Vol. XLI, No. 2-3 (Summer/Fall 1999), pp. 151-179.

Copyright (c) 1999 by The Association for Comparative Economic Studies.

All rights reserved. No part of this publication may be reproduced or transmitted in any form or by any means, electronic or mechanical, including photocopy, recording, or any information storage or retrieval system, without permission in writing from the copyright holder. 


\title{
State-Owned versus Township and Village Enterprises in China*
}

\author{
Enrico C. Perotti \\ University of Amsterdam and CEPR \\ Laixiang Sun \\ International Institute for Applied Systems Analysis, Laxenburg, Austria \\ and \\ Liang Zou \\ University of Amsterdam
}

Journal of Economic Literature Classification Numbers: L20, P32, P42.

This paper presents an up-to-date survey of the comparison issue between state-owned enterprises (SOEs) and township-village enterprises (TVEs) in China. Although TVEs are at a disadvantage in areas such as technology, labor skills, education levels of staff, access to bank loans and government supports, they have important advantages in ownership and governance structures, personnel systems and labor relations, and conditions of institutional arrangement. These advantages apparently have outweighed the disadvantages, allowing the TVEs to outperform SOEs and successfully expand their market shares that previously belonged to the SOEs. However, our analysis also reveals that SOEs may not have performed so badly if their broad social contributions other than reported profits are also taken into account. In conclusion, we argue that both SOEs and TVEs need to reform their ownership and governance structures. In particular, if TVEs are to develop further during the next century, they cannot avoid the grassroots democratization.

\footnotetext{
* Part of this paper was written and revised while Laixiang Sun was visiting the World Institute for Development Economics Research (UNU/WIDER) in Helsinki and Liang Zou was visiting the Hong Kong Baptist University. They gratefully acknowledge the gracious support of their hosts. While fully responsible for any remaining errors, all the authors wish to thank Robert C. Stuart, the editor, and an anonymous referee of this journal for their comments and advice.
} 


\section{Introduction}

While China's overall economic reform has resulted in considerable achievements in the past two decades, some deep structural problems remain, one of which is the long-lasting inefficiency of the state-owned enterprises (SOEs). Although there have been disputes over the total factor productivity of SOEs, it is widely acknowledged that a growing proportion of SOEs are losing money. According to a recent World Bank (1997) report, about half of industrial SOEs made a loss in 1996, up from one-third just two years ago. The SOE share in national total industrial output has fallen from 77.6 percent in 1980 to 28.5 percent in 1996 (SSB, 1997, p. 413), and estimated to decline further to 25 percent by the year 2000 .

The statistics seem to indicate that despite persistent enterprise reforms, the situation of SOEs is worsening, or at least has had little improvement. Is this completely true? Or how bad is the performance of SOEs and why? This paper will show that official statistics do not provide a complete picture of the performance of SOEs. Moreover, where they underperform nonSOEs, their underperformance relative to commercial measures can be partly explained by their attention to certain social objectives.

In contrast, township and village enterprises (TVEs), which are either collectively established by or initially based on and closely associated with rural communities such as townships and villages, have developed rapidly and become engines of China's rapid economic growth.' In 1995, the TVE sector produced nearly 30 percent of China's gross domestic product (GDP). In the same year, industrial TVEs produced about half of the total industrial value added, profit, and output. ${ }^{2}$ In 1980, there were 1.4 million TVEs with 30 million employees. By 1996, there were 23.4 million TVEs with 135 million workers (SSB, 1997, pp. 399-400). Their real total output increased by an average rate of 21 percent per annum from 1978 to 1995 (SSB, 1996, pp. 389 and 403), and the growth rate of their real value added remained over 18 percent in 1996 and 1997 (People's Daily, 28 February 1998). The TVE exports increased from US\$8 billion in 1988 to US\$84.3 billion in 1997. The TVE shares in the national total export rose from 16.9 percent in 1988 to 46.2 percent in 1997 (see, Table 2).

The TVE miracle brings about a series of interesting questions. Typically, the core TVEs are collectively owned by the citizens in rural communities such as townships and villages. In this sense, TVEs are also public enterprises like SOEs. In addition, TVEs are usually competitively disadvantaged in comparison with SOEs in such areas as technology, labor quality and skills, accesses to bank credit, information flows within the government hierarchy, distribution of key materials through official channels, and other proxies for market intermediaries. How can TVEs do so much better than SOEs? What are the real causes for the difference? Is there anything SOEs can learn from TVEs? Although some of the TVE experiences may be useful for the reform of small and medium SOEs, a careful examination of the management conditions has led us to conclude that TVEs actually have disadvantages in some crucial aspects 
as well. In other words, the ownership and governance structures of both TVEs and SOEs need to be reformed. Such reforms have already been taking place since the mid-1990s (Sun, 1999), and we expect to see more innovative structural changes in both sectors.

This paper attempts to present a comprehensive survey of the SOETVE comparative literature, incorporating our first-hand data and some original analyses. We shall argue that the SOE performance may not have been as bad as statistics indicate, despite the fact that they have, in general, underperformed. Our viewpoint is based upon both external and internal perspectives, where the external factors refer to those beyond, and the internal factors those closely associated with, the notions of property rights, governance structure, and labor relations.

The paper is organized as follows. In section 2 , we summarize the external causes for SOE underperformance, which include their heavy social burdens, unfavorable position in taxation and pricing, and rapid de-capitalization in recent years. The failure of China's state investment system and defective statistics have indeed contributed to the SOEs' underperformance. Section 3 explains why TVEs have been so successful, with focus on the factors extrinsic to ownership. In sections 4 and 5 , we focus on the internal factors that lead to the different performances of SOEs and TVEs. Section 4 highlights the differences of the governance structure between SOEs and TVEs. Section 5 examines the personnel systems and labor relations in TVEs and SOEs, comparing the incentive and supervision mechanism of managerial and labor behavior. The last section contains some concluding remarks.

\section{External Causes for SOEs' Underperformance}

Undoubtedly, the development pace of the SOE sector has lagged behind that of the non-state sector. However, as we shall show, the SOEs' performance may actually not be as bad as statistics or the coverage by the Western media have indicated. While arguing that SOE underperformance may be partly justified by their considerable contribution to the overall social security, we have no intention of joining the debate over the measurement of efficiency or productivity of SOEs. We agree that SOE performance has not been, at least, as good as that of TVEs during the reform period. Many external factors have contributed to the reported poor performance of SOEs, among which we identify four of them that we consider most important.

\subsection{Social Responsibilities beyond Profit-Seeking}

The heavy social burden may be one of the predominant factors undermining the economic efficiency of SOEs. An SOE has never been a pure economic actor. It has historically had many other functions beyond profitseeking. These include political support to the government, expansion of em- 
ployment, and provision of various social services and securities, such as housing, education, health insurance, and pensions. What distinguishes the Chinese SOEs from their counterparts in Eastern Europe is that in China each SOE, particularly large and medium sized, forms a resident community or small society in which all kinds of social services and facilities are provided by the enterprise. The manager of the SOE is more like a mayor or tribal chief. Traditional Chinese family values and employment pressure may have strengthened such welfare obligations, making them difficult to change. The increasing burden for providing a large set of public goods to its community members has severely hindered the development of SOEs.

Taking pension provision as an example, as the urban population ages, SOE pension payments have been mounting rapidly in terms of both absolute amount and relative share in the total wage payment. In 1980, the SOE sector had about 6.3 million retired employees and the ratio of the retired over the in-post was $1 / 13$. By 1996 , the retired in the SOE sector had reached 25.2 million and the ratio of the retired over the in-post rose to $1 / 6$. Accordingly, the proportion of pension expenditure in the total wage payment increased from 6.9 percent in 1980 to 22.6 percent in 1996 (SSB, 1997, pp. 121, 749-750). While the newly established SOEs have been relatively free of the pension burden, older SOEs have become weighed down by the increasingly heavy pension provision.

To what extent is the SOEs' efficiency directly affected by their provision of the large set of public goods to the urban population? It has been estimated that about 40 percent of the difference in profitability between SOEs and TVEs can be attributed to social welfare provision of this kind (Xiao, 1991). In addition to the direct contribution, while functioning as a small society, an SOE has de facto provided unemployment insurance payment to its redundant employees (on-the-job unemployment). It is estimated that about 20 percent of employees in the SOE sector are in fact redundant (Bell, 1993).

The above facts indicate that these heavy social burdens may justify a large part of SOE losses in a society where a functional social security system is absent. Without SOEs many of these social costs would go to the governments at different levels.

\subsection{Unfavorable Position in Taxation and Pricing}

Along with the marketization reform, the traditional advantages that SOEs have enjoyed, such as easy access to key materials, credit, and captive markets, have gradually diminished. However, many disadvantages have persisted and two of them are critical.

The first one is the SOE's unfavorable taxation position. Although many tax reforms conducted in the past two decades were intended, with different degrees, to reduce the SOE heavy tax burden, taxes collected from the SOE sector have accounted for more than 70 percent of the total government 
revenue (SSB, 1997, p. 238). By 1995, the SOE sector produced about 44 percent of GDP, but contributed 71 percent of national fiscal revenue. ${ }^{3}$ Before the 1994 tax reform, the nominal tax rate of corporate income for large and medium-sized SOEs was 55 percent, 35 percent for private enterprises, 33 percent for foreign-invested enterprises, and progressive tax rates ranging from 7 percent to 50 percent levied on small SOEs and collective enterprises, including TVEs. The reform unified the corporate tax rate to 33 percent for all kinds of domestic enterprises (Beijing Review, 14-20 March 1994, p. 11). However, except for these shifts in the nominal tax rate, the SOE's contributing share to the government revenue remained unchanged (see Table 1).

Table 1:

The Contribution Shares to Government Revenue by Ownership, 1988-1995 (percent)

\begin{tabular}{lccccc}
\hline & 1988 & 1990 & 1993 & 1994 & 1995 \\
\hline State-owned firms & 71.6 & 71.3 & 71.6 & 71.4 & 71.1 \\
Collective firms & 19.7 & 18.6 & 17.3 & 17.3 & 17.2 \\
$\quad$ including TVEs) & & & & & \\
Households & 5.8 & 4.7 & 5.5 & 5.6 & 6.1 \\
Other ownership & 2.9 & 5.4 & 5.6 & 5.7 & 5.6 \\
\hline
\end{tabular}

Source: SSB(1997, p. 238).

Note: Revenue from both domestic and foreign debts is excluded.

The large difference between nominal and actual tax rates can be explained by three factors. First, there has been room for negotiating tax reduction between firms and local tax authorities (Guo, 1992). Second, tax evasion is much less difficult for those enterprises outside the state sector. According to a statistical analysis conducted by Chinese statistical officials, the accumulated sum of verified evasions of industrial and commercial taxes from 1985 to 1992 amounted to 98.27 billion yuan, being equal to about 4 percent of total taxation income in each of these years (China Economic News, 23 Aug. 1993, p. 1). The evasion of enterprise income tax is much more difficult to verify and therefore, may be used more effectively by numerous small firms in the nonstate sector. The easier access to tax evasion enjoyed by the non-state firms puts SOEs at a relatively unfair position. And third, unlike for TVEs, wage expenditure is not counted as a business cost for SOEs and must be deducted from their net profit (after sales tax). It substantially expands the income-tax base of the SOEs (Guo, 1992). 
The second disadvantage is associated with the so-called policy losses induced by the remaining price control of the state. According to Zhou (1993, p.70), of the 51 billion yuan of subsidies to loss-making SOEs in 1991, one-quarter was used to subsidize the energy producers who had to bear the very low controlled prices of their products. And another quarter was used in exchange for supplying other necessities at low state prices. In fact, many SOEs in the red are engaged in energy production (mainly coal mining), grain storage and processing, and the weapons sector.

\subsection{New Losses from New Investment Projects}

Many newly established projects in the SOE sector often become new sources of loss. These projects are typically established by local governments or industrial ministries and bureaus. The failures of these projects are the failure of China's state investment system, which has been characterized by bureaucratic co-ordination and has not yet been reformed successfully (Sun, 1997a, 1998).

As pointed out in Sun (1998), the process of investment decisionmaking in the state sector is a distribution process of rights to possess and use certain scarce state assets, including budget funds, bank loans, land, quotas of power, oil, and other key materials. The very first intention of local governments, ministries, and SOEs is to obtain and occupy as much investment and property from the distributive negotiation process as possible, so that they can reap future benefits and justify their power base. For example, if an SOE was initially assigned premises in a commercial part of a city (be it by negotiation or only by chance), then its employees can get more bonuses simply by renting out the building. Often the consequence is that when trying to establish new investment projects, the decision-makers do not care much about whether or not the project will be profitable in the future. It is good if the project is profitable, but if it is not the loss will be born by the state anyway. Such an investment expansion drive, combined with the persistent soft-budget constraint, inevitably induces investment hunger and leads to inefficient investment projects (Zou and Sun, 1996).

Before the reform, the inefficiency of the state investment system was manifested in subjective decisions of the central leaders, poor preparation and monitoring, and widespread waste of scarce resources. In the reform era, following the increase of local autonomy, the inefficiency of the state investment system has been characterized by lasting and large-scale duplication of construction at the national level, and the initiation of too many new projects at the expense of technical updating of existing assets. In the end, many projects have little value once their products face weak market demand and strong competition. There are numerous examples of this in almost all industrial sectors. For example, by the end of 1990 China had built up 167 production lines for color television sets with an annual production capacity of 20 million sets. 
The annual real output was only 10 million, thus half of the production capacity was idle. In 1993, China had 126 automobile factories and 5,000 re-equipping automobile factories with a theoretical capability of producing 1 million automobiles per year. However, most of these factories had no economy of scale by any standard and the average utilization ratio of capacity was less than 50 percent (Sun, 1997a, p. 214).

The lasting and severe investment inefficiency has caused continuous worsening of SOE capital productivity, which can be clearly revealed by the change in the incremental capital-profit ratio. During 1985-1992, the net value of fixed assets of industrial SOEs with independent accounting systems increased from 398 billion yuan to 1,098 billion yuan, an increase of 700 billion yuan. While their realized pre-tax profits increased by only 61 billion yuan, from 133 billion yuan to 194 billion yuan. The incremental ratio of fixed assets to pre-tax profit is 11.5 , indicating that every 11.5 yuan increase in fixed assets (net of depreciation) resulted in only one yuan increase in pre-tax profits. The fact that the ratio of pre-tax profits to total capital decreased from 23.8 to 9.7 percent during this period (SSB, 1993, pp. 430,437) can be, to a large extent, attributed to the failures of the state investment system.

\subsection{Capital Diversion and Statistics Bias}

Whether the official Chinese statistics are capable of providing a reliable account of SOE performance is an open question. One of the basic requirements for official statistics in any economy is to provide standardized and relatively stable data. These requirements may not allow the official statistics to capture tactical activities used by firms in a rapidly changing economy. Among these tactical activities, several have significantly contributed to the under-reporting of SOE performance. These include implicit diversion of assets and profits from SOEs, the SOE-foreign joint venture, and the SOE's incentives to under report their profit potential owing to the so-called ratchet effect.

The implicit diversion of assets and profits from the SOE sector to the collective sector is induced by SOE social responsibilities. In order to create jobs for the children of their employees, most SOEs have to set up some new branches, making use of technologies and equipment of the parent SOEs, often free of charge. These branches are officially independent identities, which are usually registered as collective firms. In fact, these firms typically depend on the parent SOEs for survival and development. Once discovering such diversion as a convenient channel to avoid tax and to increase the incomes of the managers and employees, many SOEs also transfer part of their profits to these daughter firms in the name of subsidies and employment creation (Qian, 1995).

A survey (conducted in 1992) on 760 collective enterprises set up by SOEs in Shandong province showed that 54 percent of them were using 6.07 
million yuan of parent SOE assets freely. Some SOEs tend to transfer profitable products and technologies to their daughter subsidiaries (Guo, 1992, p.49). Often such subsidiary companies make profits by simply selling the low-price planned goods from the parent SOEs at going market prices.

Thanks to many preferential policies for Sino-foreign joint venture and their own expansion drive, SOEs have had strong incentives to set up joint ventures with foreign firms. Such ventures are not counted as a part of the SOE sector in official statistics, although the SOE in such a joint venture is often the de facto majority investor or controller. In addition, many of the (more successful) SOEs have been transformed, partly or fully, into joint stock companies, which is classified into the category of "other ownership firms" despite the state holding the majority share. In 1994, for instance, the output value of these state share-holding companies was equal to 17.6 percent of that of the SOE sector (SSB, 1995, p. 375). Therefore, it is likely that the official statistics suffer selection bias in reporting the poor performance of the SOEs.

SOE management has been monitored by responsibility contract during the reform era. This monitoring system seems to have transferred the ratchet effect from output target to profit target. A higher profit achievement of any year means that a higher target will be set up for the next year, which has been vividly likened as "lashing the faster oxen". As a consequence, SOEs have a tendency of under-reporting their profitability to a certain degree, often reporting that they are just breaking-even allowing for a better negotiating position in setting future profit targets (Zhou, 1993, p.71).

In comparison, TVEs have few such concerns and, in fact, the contrary seems more likely. Local government officials tend to encourage their subordinates to exaggerate profits of TVEs, which can be used as achievements to speed up the promotion of their own administrative career and to compete for more bank loans. Though it is impossible to have an accurate picture, one recent news report may be informative: the director of the statistics bureau of Changzhou city in Jiangsu province, one of the areas with the highest level of TVE development, was arrested because he invented high figures for local TVEs to reach projected profit targets (The Chinese Times, June 15,1995$)$. Clearly, he might have been encouraged, even pressured by some higher level officials.

To sum up, considering all these factors as discussed above, we come to a conclusion that the actual performance or efficiency of SOEs may not have been as bad as indicated by the statistics. An additional observation is that it was SOEs, not TVEs, that typically operated at the frontier of new product development (Jefferson, 1993, p.3).

\section{Conditions Contributing to the TVE Miracle}

The TVE phenomenon is unique in the sense that the emergence of rural entrepreneurs and enterprises has not been experienced in any other country 
on such a large scale and at such a rapid rate. Its roots can be traced back to the late 1950s, but its development was not truly noticeable until the late 1970s when China began to carry out reforms and to open up to the outside world. The TVE development so far is not an outcome of any carefully designed policy or plan. The government policy changed from tolerance to encouragement during the 1980 s, only after recognizing that the TVE was a vehicle to increase rural income, and more importantly, to absorb a large amount of rural labor surplus without much need for state investment - a serious problem which had been confronting the Chinese governments at all levels (see Jin and Qian 1998 for more details).

Generally speaking, there has been an overall favorable environment for TVE growth during the reform period, providing both incentives and disciplines for township and village governments and TVE managers in the process of TVE development.

\subsection{Hard Budget Constraints Confronted by Township and Village Communities}

In China, the central, provincial, municipal, prefecture, and county governments all have sufficient authority to regulate markets through administrative methods and to be involved in credit decisions through both vertical and regional accountability (dual coordination). Ex ante, governments at the level of the county or above are directly involved in the formulation of credit plans and can direct specialized banks to make loans. Ex post, governments have the authority to decide whether or not SOEs should pay back the loans.

Township and village governments (TVGs) have no such authority. A TVG cannot protect its TVEs by erecting trade barriers to keep out competition simply because the market within a community is both too small and limited. TVGs have no access to the state banking system, because all townships and villages are historically institutionalized as part of the traditional rural sector whereas the banking system is a part of the modern urban sector. Likewise, all staff members of state banks are registered in the urban residency registration system and have no links with the rural sector except through business dealings.

As a consequence, state banks have typically followed the commercial principles in making loans to TVEs. Often, they ask TVGs to act as guarantors of investment loans. If a township or village has a poor credit repayment record, state banks can refuse the loan application and, additionally, they can withhold interest payments and some of the principal from the bank accounts of the community or its TVEs. Each TVG well understands that a community may be able to delay debt repayments over the short term, but that it cannot delay them indefinitely. Meanwhile, a poor credit record implies that the community must depend on self-financing for future development and debt servicing. This is not possible even in agricultural communities, for which bank 
credits are needed seasonally for the purchase such inputs as seeds, chemical fertilizers and pesticides, etc.

The above facts force township and village communities to confront the pressure of market competition and a hard budget constraint. Though subsidizing across TVEs within a community is possible, the extent of such subsidies is very limited. Thus, in reaction to the economic austerity in 1989 and 1990, several million TVEs were closed down or taken over by other TVEs (Zou and Sun, 1998, Table 1). In contrast, the losses among SOEs soared, although only a handful actually went bankrupt. A 120 billion yuan credit relief operation was initiated in the fourth quarter of 1989 to write off non-performing inter-enterprise credits, mainly inter-SOE credits (Portyakov 1991).

\subsection{Initiatives and Supports of Community Government}

Core TVEs are typically initiated or directly established by TVGs. Motivated by revenue generation, employment creation, and the strong desire of the community for improving living standards and increasing wealth, TVGs have been strongly enthusiastic developing TVEs. This enthusiasm has been further strengthened by an increasing responsibility for improvement of local education, infrastructure, and social welfare, which have been gradually shifted from upper levels of government to TVGs.

Three critical contributions of TVGs to TVEs have been outlined by Chang and Wang (1994, pp. 443-44). First, because TVGs are part of a large governmental system with broad powers, and because of the long tradition of authoritarian government in China, the full support of TVG can provide community members and other TVE stakeholders with a sense of security which is needed to achieve long-term development. Second, TVGs can offer managerial inputs to TVEs in several ways. Because the market is in its infancy and ordinary citizens who have suitable market-oriented talents are a scare resource, TVGs are essential in the organization of major economic and political activities within their jurisdiction. Without a market or other social mechanisms, TVGs are often the only available local institutions with the authority to settle disputes which arise in the process creating TVEs. Third, TVGs can play an essential role in gaining access to outside resources, particularly bank loans. In addition to these three contributions, TVGs are not only the guarantors of TVE loans, but also the executors of the collective financing and debt repayment system. This collective financing and debt repayment system represents another support for TVE growth. All the funds required for the start-up of a new TVE can be borrowed from existing TVEs with the help of the TVG (Wong et al., 1995). This system also offers TVGs the power to initiate and co-ordinate internal reorganizations or takeovers so that communities can avoid the social and economic costs of bankruptcy and of takeovers by outsiders (Sun, 1997b; Zou and Sun 1998). 


\subsection{Integration into World Economy}

Geographically, TVEs are most developed in the coastal provinces of Guangdong, Fujian, Zhejiang, and Jiangsu. These provinces, both historically and today, have close links with the overseas Chinese in Hong Kong, Taiwan and Southeast Asia. TVE development in these provinces has well fitted in the requirement of international division of labor and in the considerable comparative advantages of rural China.

For overseas Chinese investors, the attractions of TVEs in the coastal areas manifest themselves in (a) a large number of cheap and well-disciplined Chinese rural laborers released from the successful agricultural reform and development in the early 1980s; (b) various preferential treatments in tax exemption, currency conversion and remission of profit granted by the opendoor policy; (c) flexible and relatively convenient approval procedures for their investment projects in the rural society; (d) proximity to their bases; and (e) cultural convenience and traditional family or kinship network. It is also conceivable that (a), (b) and (c) are attractive to other foreign investors.

Foreign investments have played an important role in TVE development. Foreign investors have brought in scarce foreign capital and relatively advanced technology and management skills, and their marketing networks abroad provide easy access to international markets. Compared with domestic buyers, there are less problems of the (widely spread) inter-enterprise debts, because exports also guarantee payment, as it is due mostly upon delivery.

Thanks to the compatible incentives and comparative advantages, TVE achievement in exports has been most impressive. Table 2 presents TVE export growth in terms of both total scale and relative share. It can be seen that during the ten year period of 1988-97, the TVE's shares in the total national export increased from 16.9 to 46.3 percent. The TVE's total export value increased from US $\$ 8.02$ to 84.6 billion. This is equivalent to an annual growth rate of 26.5 percent in terms of US dollars, despite the devaluation of yuan from 3.7 to 8.3 yuan per US dollar. It is worth mentioning also that the TVE's export growth has been largely contributed by the TVEs with dominant community ownership (People's Daily, 6 Feb. 1998).

Table 2:

The Growth of TVE Export, 1988-1997

\begin{tabular}{lccccc}
\hline & 1988 & 1991 & 1993 & 1995 & 1997 \\
\hline TVE export (billion US dollars) & 8.02 & 14.8 & 38.1 & 64.5 & 84.6 \\
TVE share in total export (\%) & 16.9 & 20.6 & 41.5 & 43.3 & 46.3 \\
Average exchange rate (yuan/\$1) & 3.718 & 5.327 & 5.761 & 8.369 & 8.270 \\
\hline
\end{tabular}

Sources: TVE Yearbook (1990, p. 20; 1996, pp. 102-103), SSB (1993, p. 633; 1997, p. 587), and People's Daily (5 Feb and 22 March 1998).

Note: TVE export includes direct and indirect (e.g. in the form of subcontracting with SOEs and foreign companies) exports, and charges on processing for foreign firms (TVE Yearbook, 1996, pp. 122-123). 


\subsection{Unique Market Opportunities}

To a large extent, TVE success also depends on the unique opportunities created by China's market liberalization especially relaxation of state monopoly over industry. The protected industrial sector was effectively opened to new entrants beginning in 1979. A large number of TVEs started up and rushed to take advantage of sharing the monopoly profits in the industrial sector. For these early entrants, the average rate of net profit on capital was 32 percent and the total rate of profit and tax per unit of capital was 40 percent (SSB, 1993, pp. 396-397). Of course, continued TVE entry gradually created and intensified competition, inducing monopoly profits to decrease and finally to vanish. However, the windfall profits enjoyed by early entrants in the late 1970s and early 1980s greatly contributed to the TVE takeoff.

In the early years of TVE development, there were many empty niches in the consumer goods market (processed foods, clothes, etc.) and primarily processed products markets, mainly owing to lasting shortages induced by the inefficient command economy. Not surprisingly, TVEs jumped to meet demands of these markets. Moreover, the rapid economic development in both urban and rural areas has created a whole series of new markets - a good example is building construction and building materials production in both urban and rural areas, where TVEs have dominated these industries since the mid-1980s (Naughton, 1996, pp. 150-151).

Meanwhile, the two-track system of market and planning has also eased constraints, providing TVEs with access to raw materials and market shares outside the state plan. They can afford higher input prices by setting up higher prices for outputs, or by simply using low quality input to produce cheap and poor quality goods to meet the corresponding demands.

\subsection{Flexibility due to Size and Accounting System}

Most TVEs are small in size and engage in labor intensive industries with low asset specificity. By 1996, the average size of township enterprises was 73 employees per firm and that of village enterprises was 26 employees per firm. In the earlier years, the average TVE size certainly was smaller (SSB, 1997, pp. 399-400). This makes them very flexible to react to market changes, to switch products, and to catch new market opportunities.

The accounting system in TVEs has been much less standard and strict than in SOEs. Only the TVE owners are accountable for bookkeeping, and not all of the income and expenditure need to go through banks. Thus, they can use such flexible financial and bookkeeping systems to develop their business. TVEs typically pay the highest salaries to their marketing staff, which can be more than ten times an average worker's income. TVEs have enjoyed the flexibility to pay higher commission, send gifts, or even offer bribes to 
government or SOE officials so as to get low-price inputs or materials in shortage and to expand market shares of their products.

In contrast, these conveniences have rarely been possible for SOEs. The accounting systems of SOEs have been much more standardized, and is controlled by a nationally uniform accounting inspection system - with careful supervision of such items as wages and travel expenses.

\subsection{Support from SOEs}

The growth of TVEs in peri-urban areas has been facilitated by direct co-operation between urban SOEs and rural TVEs, mainly in the form of subcontracting. In the suburban areas of Beijing, Tianjin and Shanghai, an estimated 60-80 percent of TVE output was produced by firms subcontracting with large urban SOEs in the early 1980s (Industrial Almanac, 1949-1984, p. 50). In Jiangsu and Zhejiang provinces, where TVEs have dominated the local economies since the mid-1980s, the proportions were only slightly lower in the mid1980s. Linkages with Shanghai SOEs in these two provinces have played a decisive role in their TVE development (Tao, 1988, p. 100).

Why are urban SOEs motivated to cooperate closely with TVEs? Naughton (1996, pp. 155-156) gives three plausible reasons, namely diversified supply, cheap labor and land use, and the flexibility to escape some rigid controls of the state sector.

\section{Ownership and Governance Structures of SOEs and TVEs}

It has become popular to view ownership as a bundle of rights and the firm as a nexus of contracts among various owners of different production factors (Alchian and Demsetz, 1972). Ownership structure involves many dimensions, among which the most important are the allocations of residual control rights and rights to residual benefits. An ownership structure that is consistent with the objective of firm-value maximization may require that the residual claimants, who contract for the residual benefits, bear the residual risks, the "risk of the difference between stochastic inflows of resources and promised payments to agents" (Fama and Jensen, 1983, p.302).

The governance structure of a firm refers to "the ways in which suppliers of finance to [the firm] assure themselves of getting a return on their investment." (Shleifer and Vishny, 1997). The governance structure of the SOEs is weak because the state, in the role of financing SOEs, has no assurance to get adequate returns on the investments. The governance structure of the TVEs is better defined and appears to be much more effective. The main suppliers of finance to the TVEs are the township or village households and outside creditors. Acting on their self-interests, these finance suppliers have all the incentives to make sure that their investments will not be appropriated. Alter- 
natively, without an adequate governance structure, a TVE would find it very hard to get any project financed by outside creditors.

Separation of ownership and control, or, in more intuitive terminology, of finance and management, is likely to lead to agency problems. This refers to self-interested managerial behavior that imposes agency costs on the firm or on the absentee owners' welfare. Optimal incentive contracting may ameliorate some of these costs, but owing to informational asymmetries, monitoring costs, or other market imperfections, agency problems are in most cases inherent in the separation of ownership and management.

As with China's SOEs, the agency problems are further aggravated by the conflicting roles assigned to the managers and to the supervising bodies, and by the fact that SOEs' assets are akin to public goods that suffer from free-riding problems (Jefferson, 1998). On the other hand, TVEs are much less affected by these problems. The TVG usually has close relationships with the managers of the TVEs. Monitoring costs are lower, and thanks to their close relationships, information could be shared by the member firms within the community. Furthermore, incentives can be aligned more easily because of member firms' common interests and the fact the TVEs share financial risks under the umbrella of the TVG (Zou and Sun, 1998). However, along with the expansion of the TVEs as they become more successful, the traditional close ties among the community member firms may be loosened. Powerful TVEs may eventually free themselves from the control of the TVG, and new conflicts among the TVEs or between TVEs and the TVG could emerge. These would likely result in more serious agency problems as well.

\subsection{Problems Inherent in SOE Ownership and Governance Structures and Choices for SOE Reform}

An SOE is, by legal definition, owned by the Chinese people. Being owned by 1.2 billion people inevitably means nobody directly owns the firm. As analyzed in Jefferson (1998), this widely dispersed and ambiguous ownership structure induces the excludability problem. In different periods and following the policy shifts, SOEs have been subject to opportunistic behaviors and appropriations by those who have direct control of or influence on the firms' assets. These appropriations may include, e.g., asset stripping by managers and other insiders; shirking by workers; predatory taxes, fees and bribes levied by government officials; and non-pecuniary benefits for employees and their relatives in the forms of housing and social services.

While the 1.2 billion people have no way to exercise direct control over SOEs, the real control rights are delegated by the central government to ministries, local governments at different levels and their industrial bureaus. In order to limit the opportunistic behaviors of managers and officials at lower levels, the governments at higher levels have sufficient reasons to keep tight control over SOE operation. Thus government interventions become inevi- 
table. On the other hand, the state has to bear the losses made by SOEs in return, assuming an unlimited liability for SOEs. The asymmetry between lower jurisdictions that are interested in extracting value from the SOE pool and higher jurisdictions that replenish value, through either direct subsidies or the state bank system, creates a serious moral-hazard problem for opportunist local officials. It has induced an accumulation of bad loans and non-performance debt within the SOE sector that renders the financial system vulnerable to external shocks and crises (Jefferson, 1998).

How should China reform the ownership and governance structures of SOEs? Diversified alternatives have been proposed by scholars and experimented with in China, which include selling, leasing, and management and employee buyout (MEBO) of small and some medium SOEs, SOE equitization through equity joint venture with foreigners, and restructuring SOEs into shareholding companies. It is widely acknowledged that China's enterprise reform is a progressive process of reassigning property rights, reducing transaction costs, and exchanging these rights among officials, managers within the firm, and outside entrepreneurs and firms in search of sales, mergers, and acquisitions (Sun, 1997b, pp.16-23; Gu, 1997; Jefferson et al., 1998). Though SOE property rights are not well-defined, the entering of SOEs into an economy where market-mediated exchanges of property rights are possible does define the opportunity cost of state ownership (Jefferson, 1998). The increasing opportunity costs of SOEs have motivated and will further stimulate the SOE reform in China.

\subsection{Relative Advantages of TVE Ownership and Governance Structure}

TVEs are under the direct jurisdiction of their TVGs. The government-enterprise relationship is much simpler and more direct than that of SOEs. In terms of the owner-management relationship, community members as owners do have incentives to monitor the TVG officials and TVE management, though the real effectiveness varies across different communities. Because community members, as owners, possess the right to derive both shortrun and long-run residual benefits from the TVE's operation, when necessary they are willing to give up short-run benefits, such as dividends, in exchange for long-run more profitable benefits. Here, the term "benefits" can be broadly defined as including job opportunities and security, pension funds, and communal welfare programs in housing, health care, irrigation, road construction, and other infrastructure (Chang and Wang, 1994; Sun, 1997b).

Although the residual control rights exercised by TVG may imply a certain risk of bureaucratization, the control by the government over implementation and coordination of internal reorganization, or over the takeover process, does sidestep the social and economic costs of bankruptcy through 
court action or of takeover by outsiders. This control is quite similar to that exercised by the main bank in a Japanese Keiretsu.

Because the residual control rights of TVEs within a community is held by TVGs, the community becomes a de facto corporation or "mini conglomerate", facing a hard budget constraint (Section 3.1). Under the pressure of intense competition, this arrangement can facilitate a consensus among community members, TVG officials and TVE managers and workers to maximize profits even by sacrificing all or part of wage income. Moreover, because a community is diversified in an economic sense, it can diversify the business risk. A township or village can rather easily create several small-scale TVEs in manufacturing, agriculture, commerce, construction, and transportation and then expand the size of these TVEs (Zou and Sun, 1998).

A community can be seen as a small society, in which the citizens/ owners can vote by a show of hands in semi-competitive elections for community officials. In wealthier villages and villages that enjoy a large TVE economy, this is particularly true (O'Brien, 1994, pp. 47 and 51; The Economist, 2 Nov. 1996, pp. 81-83; Howell, 1998). The villagers may also directly participate in discussions with community leaders. These avenues contribute to the resolution of the agency problems and help reduce costs of organization.

A community can also be seen as a corporation, governed by, e.g., a system of responsibility contracts or subcontracts. Such a system can be arranged between the community representative assemblies and the community government, between the government and the TVEs, and within the TVEs. These contracts and subcontracts have facilitated the solution of monitoring problems within the community and within the TVEs (Lin, 1995; Wong et al., 1995).

For the large-scale TVEs requiring access to domestic and international capital markets, a further clarification of property rights is necessary. However, this does not mean that the only alternative is the distribution of shares among individuals. The community as a collective equity holder and the TVG as the executive equity holder may still possess comparative advantages. Even if each citizen becomes a shareholder, it may still be more efficient if the TVG can act as the representative of local shareholders in the exercise of their residual control rights over the TVEs (Vermeer 1996). In this connection, the democratization recently exercised in China's villages is of decisive importance for future TVE development.

\subsection{Disadvantages Inherent in TVE Property Rights Arrangement}

The so called "mechanism degeneration" of TVEs has been widely reported since the early 1990s (see, e.g. Ministry of Agriculture, 1997). Many aspects of mechanism degeneration can be linked to the problems inherent in 
TVE ownership and governance structures. Among them, two are often pointed out.

First, TVGs are not purely economic actors. As TVEs mature, the objectives of TVG officials are coming increasingly into conflict with those of TVE managers, although initially these two sets of objectives were quite similar (Ren et al., 1990; Wang 1990; Shi and You, 1997). TVGs have assigned priority to raising employment, local prosperity and financial revenue. This could hinder the stable, long-term development of TVEs. The powerful control rights of TVGs could thus lead to unfavourable interference into TVE management. TVGs also seem to be shifting the responsibility for the overall development of rural communities onto TVEs. As a result, many TVEs are now also experiencing redundant employment and increasingly heavy social burdens. In this, they are becoming quite similar to SOEs in many ways (Byrd and Lin 1990, pp. 125, 304 and 351, Shi and You, 1997; Xu and Zhang, 1997).

Second, bureaucratization and corruption among TVG officials and TVE managers are growing. In those townships and villages where the development of grassroots democratization has lagged behind, the problem of who monitors the monitors becomes increasingly serious. This is because there is a lack of effective checking and restraint devices to curb corruption behavior of those increasingly powerful TVG officials. For example, many TVEs are becoming "purses" of their TVGs, required to pay all sort of expenses for TVG officials. And many TVE managers are stripping TVE assets for their own interests (Shi and You, 1997).

Although there have been supervisions from county governments as highlighted in Che and Qian (1998), this kind of monitoring may be limited due to the problem of information asymmetry. The restraints from county governments are mainly based on disciplines of the Communist Party. This may not make sense for most officials at grassroots level, because the probability for them to get promotion into a formal bureaucrat is tenuous. Indeed, compared with the economic and social rents they enjoy from the TVEs, the career of being a low-rank bureaucrat is not that attractive. In addition, this monitoring is bound to be weak because of the communication difficulty in rural areas and there being usually a large number of TVEs and TVGs in a county.

The existence of these problems calls for further reforms of TVE ownership and governance structures and for grassroots democratization (Sun, 1999).

\section{Differences in Personnel Systems and Labor Relations}

Another important reason for the different performance of SOEs and TVEs lies in the different personnel and employment systems, which assigns the roles of managers and shapes the basic labor-management relations in SOEs and TVEs. Generally speaking, unlike in the TVE sector, there is no significant labor market for both SOE managers and workers. An SOE manager is not just an entrepreneur but also a bureaucrat and the chief of the SOE 
community. He/she has to cope with and co-ordinate conflicting interests among different stakeholders, inside and outside the SOE, and within the community. SOE employees, as the inside stakeholders of their SOE, have enjoyed a special set of social privileges, are more influential in certain areas, and are more difficult to manage than their counterparts in TVEs.

\subsection{Urban versus Rural Social Status}

China has practiced a very strict personnel control system. People are divided into different social statuses, among which the most significant differentiation is between urban and rural ones. Each Chinese citizen is registered either as urban or rural resident under a household residence registration system. The registration status depends on one's mother's status at birth. This status can only be changed due to a promotion to certain level in military service, university enrollment, or marriage plus a repeated change-of-status application and waiting for many years. As urban citizens, their food supply is subsidized and employment is guaranteed by the state. Furthermore, whether a citizen is employed in a SOE or in an urban collectively owned enterprise (COE) will further determine the different levels of his or her employee benefits. Only are urban citizens entitled to work in SOEs and to the associated welfare benefits, such as subsidized low-rent houses, life-time employment, health care, retirement pension, children's schooling and employment, and so on. This systematic arrangement is why Chinese peasants often say that the socialism has been realized only in urban China and in the state sector. This arrangement establishes a specific incentive structure for urban Chinese and SOE employees, allowing them to enjoy benefits and costs packages that are different from those for the rural Chinese.

A positive externality of this arrangement, though, is that by restricting the employment opportunity of rural citizens in cities, this system helps create a more competitive rural labor market for TVEs.

\subsection{Personnel/Employment System in the SOE Sector}

For both SOE managers and workers there has been no pressure or threat from the labor market until significant layoffs took place in $1996 .{ }^{4}$ The long-lasting reform over the lifetime employment system has had a limited effect. The system of contract employment was adopted in 1986, but is only applicable to the newly recruited workers. Before 1989 , almost 90 percent of the employees in the state sector had permanent job tenure. Until 1994, only 26 percent of SOE employees were on employment contracts (SSB, 1997, p. 113). It is also widely reported that there has been little real difference between permanent employees and those contracted prior to 1996. One may argue that the lifetime employment may not necessarily result in lower efficiency with reference to the evidence from Japan, but the difference is that Japanese firms 
are constantly facing pressure from market competition and the threat of takeover and bankruptcy whereas Chinese SOEs can depend on the ultimate protector, the state, for solving their troubles.

Managerial appointments in the SOE sector have been tightly controlled by the Party committees at different levels. Although an increasing number of technicians have been appointed as SOE managers in recent years, political consideration is still an important factor in promotion, and the dominant feature of heads of Party committees is that they have either an administrative or military background (Qian, 1995, pp. 228-230).

Although an evolving managerial labor market seems to emerge in the SOE sector (Groves, et al., 1995), its significance should not be overestimated because of the following two reasons. First, the entry to the market is far from free. According to an official survey conducted in 1995, about 80 percent of SOE managers, especially those of large and medium SOEs, are appointed through political and administrative channels (Window, March 10, 1995, p.10). The social status of SOE managers has been continuously defined by their ranks within the hierarchy of Party and government. For instance, some managers of large SOEs enjoy the rank of vice-minister. Second, dismissals rarely happen. It is a well-known practice in China for government officials or SOE managers usually to only be promoted and not demoted unless they commit important economic crimes or political mistakes. Usually, those managers who suffer certain difficulties in their SOEs will be transferred to work in other SOEs with a similar position as before. Only an early retirement results in an effective exit. Such a turnover cannot form real pressure or be a threat to most managers. Quite ironically, the competence of an SOE manager may be judged in an adverse way according to the turnover numbers: the more firms he has managed, the less professionally competent he may be. The selection of managers through bidding is only used in some small SOEs. These facts indicate that there are still both severe entry and exit barriers to the SOE managerial labor market.

\subsection{Employment System in the TVE sector}

For TVE employees, there is no guarantee of lifetime employment, the so-called "iron rice bowl". There have been an increasing number of rural surplus laborers who are released by agricultural development and pushed by regional development imbalance. Therefore, the rural labor market for TVEs has been highly competitive. TVEs can employ workers from both local communities and other places outside their communities. Thanks to the competition, there are no generous welfare benefits, housing in particular, for TVE employees. The unemployment and retirement insurance typically lies on their contracted land in their home villages. As a consequence, TVEs have enjoyed low labor cost and a clear management objective. In the meantime, a competitive labor market plus a land contracting system induces high labor mobility, 
the opportunity cost of unemployment for TVE workers being much lower than for SOE workers. If unemployed, the worst thing for them is to return to farming. This mobility combined with the bottom-line insurance may help reduce the problem of labor-management conflicts.

\subsection{Triple Role of SOE Managers}

An SOE manager not only has to be an entrepreneur but also a government official and the chief of the SOE community. The manager is a government official because he/she is assigned by the government bodies to be an agent of the state to manage the business of the SOE and to protect the interest of the owner, the state. As government officials, managers are likely to be motivated by administrative promotions, respected social statuses, and the associated fringe benefits. Although the cash salary for an SOE manager is typically fixed to be no more than three times the average salary of regular workers, he/she can be compensated by many non-pecuniary benefits such as an elevated social status, large house, and other luxurious on-the-job consumption. The levels of these non-pecuniary benefits are mainly determined by his/her official rank in the bureaucratic hierarchy. This incentive structure serves the purpose of inducing SOE managers to identify themselves with the government and the state, and to protect the interest of the state in their SOEs.

The role of bureaucrat is bound to conflict with the role of entrepreneur in any economy, because politicians or bureaucrats have to, in most cases, give priority to political control, job generation, and complaints of their constituencies rather than to profit maximization of SOEs under their control (Boycko et al., 1996).

As we analyzed in Section 2.1, each SOE, in particular large or medium sized, lives as a resident community or small society, and the manager naturally assumes the role of the mayor or chief of the community. Within a community, the power balance appears to have been well established. The Party Committee has played a key role in the appointment of upper level personnel, particularly the assistant directors and mid-level cadres. The Employees' Congress has played a dominant role in dismissal decision of workers and in distribution of social welfare. Employees also have a large influence over the decision concerning wage and bonus differentials (Jefferson et al., 1998). For the community members, the top concern is their employment security and welfare maximization, which is in conflict with profit maximization.

By way of a compromise between the roles of bureaucrat and entrepreneur, SOE managers prefer to develop smooth relationships with their superiors. These managers tolerate many kinds of predatory demands from their superiors, and pay various bills and unauthorized charges imposed by these above, thereby adding to the losses of SOEs. Table 3 presents a comparison of initial distribution patterns of 769 surveyed SOEs in 1981 and 1989. We see in the table that there is a category of "other expenses", the share of which almost 
doubles from 1981 to 1989 . Among the other expenses, the unauthorized fee imposed by superior bodies is a major component (Tang, 1992, p.9).

Driven by the interest of the SOE community and thanks to the increasing autonomy along with the reform, SOE managers now have more discretion to increase wages, bonuses, and other community welfare at the expense of earnings. It is reported that during 1986-90, the realized pre-tax profit of those SOEs within the state budget (key large and medium SOEs) increased by only 3.2 percent while the total wages and bonuses of their employees went up by 91 percent (Survey Report, 1992, p.4). It is also frequently reported that some loss-making SOEs continuously pay bonuses to their workers by using bank loans.

The unbalanced increase of employees' benefits have failed to result in better performances, because of the effective "lower level bargaining between managers and workers at the factory level," both of whom seek to maximize profit retention while distributing it as equally as possible within the firm (Walder, 1987, p.41).

Table 3:

Initial Distribution of Net Revenue in 769 Surveyed SOEs in Sichuan Province (percent)

\begin{tabular}{lrr}
\hline & 1981 & 1989 \\
\hline Profit (after sale tax) & 46.23 & 33.03 \\
Sales tax & 24.34 & 24.69 \\
Interest payment & 2.13 & 9.24 \\
Wages & 20.28 & 24.70 \\
Other expenses & 4.50 & 8.50 \\
Total net revenue & 100.00 & 100.00 \\
\hline
\end{tabular}

Source: Tang (1992).

Note: This survey is conducted by Economic Institute of China Academy of Social Sciences. The sum of shares is not equal to 100 because of rounding and compiling errors in the raw data.

\subsection{Simple Role of TVE managers}

By contrast, the role of TVE manager is simple. A bureaucratic career has very limited possibility, and thus is hardly attractive, especially for those in rich regions. The tasks and objectives of a TVE manager or management team are typically well specified in a contract between them and their TVG. They 
only need to report to the TVG. This simple principal-agent contract also makes their work considerably easier and more efficient.

The major compensation for TVE managers includes direct pecuniary benefits in various forms such as higher wages, year-end bonuses and contract fulfillment bonuses. These bonuses are closely linked with the TVE performance and thus can be considered as a kind of sharing scheme of residual benefits. Typically, the bonuses of TVE managers are not only related to their own TVE performance but also decided through comparison with the performance levels of other TVEs in the same township or village. This horizontal comparison has generated competition pressure among managers of different TVEs (Wu et al., 1990, p. 332).

TVE managers also face competition and threat from the managerial labor market. They are not guaranteed lifetime status, and their terms are fixed for a limited period. As a result, over time, entrepreneurship has developed in the TVE sector. TVE managers are becoming more experienced and professionally competent, and more capable to deal with market competition.

The evaluation practices are also different in the SOE sector and TVE sector. TVE managers are evaluated mainly by fulfillment of profit targets. But in the SOE sector, under the current institutional arrangement and market conditions, it is hard for the superiors to figure out which losses are caused by external factors, which are inherited problems of the SOE, and which are resultant from the incapable mangers. For an SOE manager, it is easy to list a number of objective reasons that can serve as excuses for poor performance.

\subsection{Labor-Management Relations in SOEs and TVEs}

For SOE workers, there has been a lack of incentives and pressure to work hard because of the lasting egalitarian practice of income distribution, the lifetime employment system, and the public goods property of SOE assets.

In comparison with TVE workers, SOE workers are less disciplined and may be more difficult to manage. The labor-management conflict can turn into a personal one. For instance, if the manager decides to penalize an undisciplined worker, the worker may take it personally and make trouble or brandish threats to the manager and even the manager's family. The worker believes that any loss of the enterprises caused by his undisciplined performance will be borne by the state while any personal punishment against him will have to be borne by him individually. This adds to Jefferson's (1998) list an additional manifestation of nondiminishability property of the SOE public goods, which indicates that one person's overconsumption need not seriously constrain the ability of others to extract value from the SOE. Because of this nondiminishability, the undisciplined worker has a rational reason to think that if the manager decides to punish him then it must be out of the manager's personal intention. There is nearly a consensus among workers and managers about this. Moreover, because of such obvious nondiminishability, the punished worker can 
often get sympathy from other workers. There have even been examples where managers were injured or even killed, by workers during reforms in some places. Meanwhile, managers have no incentive to place the workers under strict disciplines at all. As a consequence, pervasive shirking and free riding become inevitable and widespread in the SOE sector.

TVE workers are much easier to disciplined and to manage. They have sufficient motivation and face strong pressure to work hard. They are motivated by the close link between their wages and performance. Piece-rate and team-responsibility-wage systems are common in the TVE sector. As for pressures, TVE employees are almost without exception contract workers, hired for the year or the season with no job security as there are many others waiting for jobs. They often work longer hours and much harder than SOE workers do, because if their performance is not satisfactory, their job contracts may not be renewed or even terminated in advance (Ho, 1994). Collectively, if business goes wrong, everybody in the firm will lose their job. Therefore, TVE workers well understand that their own future is closely tied with that of the firm, with which they have to share the risk.

The outstanding performance of TVE workers may be further explained by a kind of group or mutual monitoring at the horizontal level. This mechanism is induced by the threat of collective unemployment caused by the failure of their enterprise, in academic words, by a "cooperative culture" within a small commons (Weitzman and Xu, 1994; Jefferson, 1998).

\section{Concluding Remarks}

In this paper we have presented a comprehensive account of the issue of SOE-TVE comparison in China. The account is based on a major survey on the literature as well as first hand analysis. It is concluded that though TVEs have been confronted with comparative disadvantages in the areas of technologies, labor skills and education levels, accesses to bank loans, official channels of information and key material distribution, they have enjoyed and established more important advantages over SOEs. These can be summarized in the following major points: (a) Hard budget constraints to TVEs in general and to each township and village community in particular, whereas SOE budget constraints remain soft. (b) Relatively compatible interests and incentives within a TVE community, constantly reinforced by competitive pressures from markets and other communities, whereas SOEs have continuously shared the properties of public goods and faced conflicts of interest in many aspects. One example is the conflicting roles of SOE managers, who have to be simultaneously a government bureaucrat, chief of the SOE community, and entrepreneur. (c) Flexibility due to small size, diversified community economy, and far from strict bureaucratic control, which give TVEs an advantage to capture opportunities emerging in all markets of products, labor, capital, and the domestic and international. And (d) simpler principal-agent tier, personnel 
and employment system, and labor relations, which are induced by the historical institutional arrangements in rural China and subject to the adjustments required by competition. As a consequence, TVEs have out-performed SOEs and replaced SOE positions in many areas. The TVE sector has become the number one sector in China's industrial production and export. In the near future, it will become number one sector in China's GDP generation.

In contrast, though having enjoyed advantages in technologies, government financing and supporting, SOEs have suffered from many problems inherent in SOE institutional arrangements and their ownership and governance structures. Due to the widely dispersed and ambiguous SOE ownership structure and the multiple principal-agent tiers, the SOE sector has suffered most serious agency and asymmetric information problems. There are large numbers of stakeholders around each SOE, all having sufficient incentive to extract value from the SOE but with much less incentive to put their efforts into the SOE. This is the essential reason why the SOE financial situation increasingly becomes worse while their output expansion continues - although the real performance of the SOE sector is better than what is indicated by official statistics if the SOEs' broad social contributions are taken into account. However, much of SOE social contributions may have been transferred into bad loans and non-performing debts in the state banking system, when the SOE sector has continued to consume about 80 percent of state bank credit funds but creates less than 45 percent of China's GDP.

Due to the broad institutional arrangements and cultural environments around and within SOEs are so remarkably different from those around and within TVEs, there seems to be no partial solution for SOEs to learn from TVEs. Facing a hard budget constraint, a survival urge placed by tough market and inter-jurisdiction competitions, and the self-initiated adaptive innovations induced by the competition and hard budget constraint may be the basic lessons TVEs can offer. These basic lessons have been appealing to not only SOEs but also TVEs to reform their ownership and governance structures, because both SOEs and TVEs have appeared to face similar problems while the initially favorable market and environmental conditions enjoyed by TVEs have gradually dissolved. Following the expansion of TVE scale and market shares, TVE mechanism degeneration has become increasingly serious in those township and villages where grassroots democratization has lagged behind. It has generated serious consequences in TVE performance since the mid-1990s (Sun 1999, Section 4.3). The central issues here are, once again, the increased agency costs and the question of who monitor the monitors. In this connection, SOEs and TVEs face the similar challenge and need to conduct similar reform on their ownership and governance structures. Interestingly, collective ownership within a small community which faces competition and hard budget constraint is more akin to the small commons such as the small fisheries in Maine, where a self-initiated effective property-rights arrangement has evolved (Jefferson, 1998). In fact, many Chinese rural communities initiated "joint stock cooperative" reform even in the 1980 s. Such a self-initiated, innovative property rights 
reform appeared well-fitting in local conditions in most cases and has become widespread in both the SOE and TVE sectors since 1992 (Sun, 1999).

China's ambitious and radical SOE reform plan has been delayed by the problem of a large number of layoffs and the shock of Asia's financial crisis. But the scenario is clear. The plural ownership structures and diversified governance structures have emerged and will become widespread in the near future, which include pure private ownership, employee stock ownership, joint stock partnership or cooperative, leasing, joint ventures, shareholding company and hybrid forms of shareholding company, and a small proportion of reformed state ownership in certain industries.

\section{Notes}

1. TVE in this paragraph is interpreted in the broader sense, i.e. including household-run and jointly owned private enterprises, which accounted for 33 percent of output and 51 percent of employment in the broader TVE sector in 1994 and tend to be much smaller in scale (Sun, 1997, p. 28). In the discussion which follows, TVEs are understood in the narrower sense of those with dominant community ownership only. We may call TVEs in the narrower sense "core TVEs" when it is necessary.

2. Sources: "Selection from the 1995 National Industrial Census", published in People's Daily, 19 February 1997; and Ministry of Agriculture, 1997.

3. The GDP share of SOEs in 1995 is estimated as follows. In 1995, the agricultural sector (dominated by peasant households) produced 21 percent of GDP (SSB, 1997, p. 42), the broader TVE sector contributed 30 percent of GDP (Ministry of Agriculture, 1997), and the urban collective, private, and foreign sectors could have produced 5 percent of GDP.

4. By the end of 1996, there were about 9 million SOE lay-offs in urban China (SSB, 1997 b, p. 31). These workers continued to be identified as SOE employees rather than unemployed. Their cash salaries are reduced by a large margin, but other non-pecuniary benefits basically remain. In addition, governments at different levels have promised and conducted programs to help them find new jobs. Because they have maintained and expect to maintain their favorable urban plus SOE social status in the future, they usually resist joining TVEs or entering the huge emerging urban labor market that has attracted tens of million rural laborers since the late 1980 s.

\section{References}

Alchian, Armen and Harold Demsetz. 1972. "Production, Information Costs, and Economic Organization," American Economic Review, 62: 777-795.

Beijing Review (weekly periodical, in English).

Bell, Michael W., Hoe Ee Khor, and Kalpana Kochhar. 1993. "China at the Threshold of a Market Economy," IMF Occasional Paper, No. 107, Washington DC: IMF.

Boycko, Maxim, Andrei Shleifer, and Robert W. Vishny. 1996. "A Theory of Privatization," Economic Journal, 106 (March): 309-319. 
Byrd, William and Lin, Qingsong (eds.). 1990. China's Rural Industry: Structure, Development and Reform, Oxford: Oxford University Press.

Chang, Chun and Yijiang Wang. 1994. "The Nature of the Township-Village Enterprises," Journal of Comparative Economics, 19, 3: 434-452.

Che, Jiahua and Yingyi Qian. 1998. "Institutional Environment, Community Government, and Corporate Governance: Understanding China's Township and Village Enterprises," Journal of Law, Economics, and Organization, 14, 1 (April): 1-23.

The Chinese Times (Huaren Shibao in Chinese), published in Japan, 1995.

Fama, Eugene, and Michael Jensen. 1983. "Separation of Ownership and Control," Journal of Law and Economics, 26, 2 (June): 301-326.

Groves, Theodore, Yongmiao Hong, John McMillan, and Barry Naughton. 1995. "China's Evolving Managerial Labor Market," Journal of Political Economy, 103, 4 (Aug.): 873892.

Gu, Edward X. 1997. "Foreign Direct Investment and the Restructuring of Chinese State-owned Enterprises (1992-1995)," China Information, 12, 3 (Winter 1997-1998): 46-71.

Guo, Zhengying. 1992. "On Problems of China's Ownership Structure,” Economic Research (Jinji Yanjiu, in Chinese), No.2.

Ho, Samuel. 1994. Rural China in Transition, Oxford: Clarendon Press.

Howell, Jude. 1998. "Prospects for Village Self-Governance in China," Journal of Peasant Studies, 25, 3 (April): 86-111.

Industrial Almanac - Almanac of China's Industry: 1949-1984. Beijing: China Labor Publishing House, 1986 (in Chinese).

Jefferson, Gary H. 1993. “Are China's Rural Enterprises Outperforming State-owned Enterprises?” Research Paper Series, Number CH-RPS\#24, Transition and Macro Adjustment Division, Policy Research Department, Washington, DC: World Bank.

. 1998. "China's State Enterprises: Public Goods, Externalities, and Coase," American Economic Review, 88, 2: 428-432.

Jefferson, Gary, John Zhiqiang Zhao, and Mai Lu. 1998. "Reforming Property Rights in Chinese Industry," in G. Jefferson and I. Singh (eds.), Reform, Ownership, and Performance in Chinese Industry, New York: Oxford University Press.

Jin, Hehui and Yingyi Qian. 1998. "Public versus Private Ownership of Firms: Evidence from Rural China," Quarterly Journal of Economics, 113, 3 (Aug.): 773-808.

Lin, Nan. 1995. "Local Market Socialism: Local Corporatism in Action in Rural China," Theory and Society, 24, 3:301-354. 
Ministry of Agriculture. 1997. "The Status of China's TVEs and the Suggestions for TVE Reform and Development in the Future," in People's Daily, 24 April 1997 (in Chinese).

Naughton, Barry. 1996. Growing out of the Plan: Chinese Economic Reform 19781993. Cambridge: Cambridge University Press.

O’Brien, Kevin J. 1994. “Implementing Political Reform in China's Villages,” Australian Journal of Chinese Affairs, No. 32 (July): 33-59.

People's Daily (Renmin Ribao, in Chinese).

Portyako, Vladimir. 1991. "The Financial Market in China," Far Eastern Affairs, No 2.

Qian, Yingyi. 1995. "Reforming Corporate Governance and Finance in China," in Masahiko Aoki and Hyung-Ki Kim (eds.), Corporate Governance in Transitional Economies: Insider Control and the Role of Banks, Washington, DC: The World Bank.

Ren, Qi, Ying Du, Jicheng Qiu, and others. 1990. “An Initial Analysis of TVE Survey in Ten Provinces," Development Research (Fazhan Yanjiu, in Chinese), March, pp. 265-288. Beijing: Beijing Normal College.

Shleifer, Andrei and Robert W. Vishny, 1997. "A Survey of Corporate Governance", Journal of Finance, 52, 2: 737-783.

Shi, Xiongru, and Jinbo You. 1997. "An Analysis of the Heavy Debt in Rural Enterprises of Southern Jiangsu," China Rural Economy (Zhongguo Nongcun Jingji, in Chinese), No. 1 (Jan.): 10-16.

SSB (State Statistics Bureaus), China Statistical Yearbook, various issues, Beijing: China Statistical Publishing House.

Publishing House. 1997b. A Statistical Survey of China. Beijing: China Statistical

Sun, Laixiang. 1997a. Aggregate Behavior of Investment in China: An Analysis of Investment Hunger and Fluctuations, PhD Dissertation, Institute of Social Studies, The Hague, London: Macmillan Press (forthcoming).

1997b. "Emergence of Unorthodox Ownership and Governance Structures in East Asia: An Alternative Transition Path," Research for Action Series RFA38, United Nations University, WIDER, Helsinki, Finland, July. ISBN 952-9520$62-\mathrm{X}$.

1998. "Estimating Investment Functions Based on Cointegration: The Case of China," Journal of Comparative Economics, 26, 1 (March): 175-191.

1999. The Evolutionary Dynamics of China's Small and MediumSized Enterprises in the 1990s. World Development Studies Series (forthcoming), UNU/ WIDER, Helsinki. 
Survey Report, by the Research Group of Policy Orientation in Vitalizing Large and Medium SOE. 1992. Published in China Social Sciences (Zhongguo Shehui Kexue, in Chinese), No. 3.

Tang, Zongkun. 1992. "Profit Transfer of SOEs and Their Reproduction Capability," Economic Research (Jinji Yanjiu, in Chinese), No. 7 (July).

Tao, Youzhi. 1988. The Southern Jiangsu Model and the Road to Prosperity. Shanghai: Shanghai Academy of Social Sciences (in Chinese).

TVE Yearbook - Statistical Yearbook of China's Township and Village Enterprises, various issues, Beijing: China Agriculture Press.

Vermeer, Eduard B. 1996. "Experiments with Rural Industrial Shareholding Cooperatives: The Case of Zhoucun District, Shandong Province," China Information, 10, 3/4 (Winter 1995/Spring 1996): 75-107.

Walder, Andrew. 1987. "Wage Reform and the Web of Factory Interest," China Quarterly, March.

Wang, Xiaolu. 1990. "Capital Formation and Utilization," in W. Byrd and Q. Lin (1990)

Weitzman, Martin L. and Chenggang Xu. 1994. "Chinese Township-Village Enterprises as Vaguely Defined Cooperatives," Journal of Comparative Economics, 18, 2: 121145.

Window of Hong Kong (published in Hong Kong), March 10, 1995.

Wong, John, Rong Ma and Mu Yang. 1995. China's Rural Enterprises: Ten Case Studies. Singapore: Times Academic Press.

World Bank. 1997. China's Management of Enterprise Assets: The State as Shareholder. Washington DC: World Bank.

Wu, Quhui, Hansheng Wang and Xinxin Xu. 1990. "Non-economic Determinants of Workers Incomes," in W. Byrd, and Q. Lin (1990)

Xiao, Geng. 1991. "Managerial Autonomy, Fringe Benefits, and Ownership Structure," Research Paper Series, No 20, Socialist Economies Reform Unit, Country Economics Department, World Bank

$\mathrm{Xu}$, Zhimin and Jianliang Zhang. 1997. "Rapidly Increased Capital versus Decreased Capital Efficiency in Township and Village Enterprises: Survey over TVEs in Suzhou of Jiangsu Province," China Rural Economy (Zhongguo Nongcun Jingji, in Chinese), No. 3(March): 51-58. 
Zhou, Xiaochuan. 1993. "Privatization versus Minimum Reform Package," China Economic Review, 4, 1 (Spring): 65-74.

Zou, Liang and Laixiang Sun. 1996. "Interest Rate Policy and Incentives of Stateowned Enterprises in the Transitional China," Journal of Comparative Economics, 23, 3 (Dec.): 292-318.

1998. "A Theory of Risk Pooling and Voluntary Liquidation of Firms: With an Application to Township and Village Enterprises in China," Tinbergen Institute Discussion Paper, TI 98-123/2, Amsterdam: Tinbergen Institute. ISSN 09290834. 
